\title{
Incorporating sea-surface temperature to the light-based geolocation model TrackIt
}

\author{
Chi H. Lam ${ }^{1, *}$, Anders Nielsen², John R. Sibert ${ }^{3}$ \\ ${ }^{1}$ University of Southern California, Marine Environmental Biology, 3616 Trousdale Pkwy, AHF 107, Los Angeles, \\ California 90089, USA \\ ${ }^{2}$ Technical University of Denmark, National Institute of Aquatic Resources, Jaegersborg Allé 1, 2920 Charlottenlund, \\ Denmark \\ ${ }^{3}$ Pelagic Fisheries Research Program, Joint Institute for Marine and Atmospheric Research, University of Hawai'i at Mãnoa, \\ 1000 Pope Road, MSB 312, Honolulu, Hawaii 96822, USA
}

\begin{abstract}
Archival and pop-up satellite archival tags have been widely used to study the movement dynamics in many marine pelagic species. Recent advances in light-based geolocation models have enabled better estimation of the geographical positions of tagged animals. In particular, TrackIt, a state-space model with the Kalman filter, uses only light data from a tag for estimating positions and does so independently of manufacturer calculations. This approach is a complete break from previous geolocation methodologies, which rely on manufacturer-processed positions as an input. In this paper, a unified model is presented to extend TrackIt to incorporate satellite sea-surface temperature (SST) matching, an approach that has been demonstrated to improve accuracy. The performance of various satellite SST imagery products is also evaluated by the comparison of SST-inclusive models against the basic TrackIt model using only light information. Three new model parameters (bias, error and smoothing radius) are introduced for handling SST observations. Analyses based on double-tagging comparisons show that the overall accuracy of TrackIt increases with the incorporation of SST, even when the resolution of the matching satellite product is rather coarse. At the same time, the model accuracy can decrease when the SST observations do not exhibit any strong trends, rendering SST matching less informative. The incorporation of SST within this generic and statistically sound modeling framework illustrates how TrackIt can readily be extended to utilize new data streams, such as geomagnetic data, which will become available with the next generation of archival tags.
\end{abstract}

KEY WORDS: Light-based geolocation · Sea-surface temperature · TrackIt · Archival tag · Pop-up satellite archival tag $\cdot$ State-space model

Resale or republication not permitted without written consent of the publisher

\section{INTRODUCTION}

Electronic data storage tags, also known as archival tags, provide a powerful tool to study marine animals continuously over time scales ranging from days to years within their oceanographic environment (Arnold \& Dewar 2001, Greene et al. 2009). These tags give us a new perspective on the daily activities of individuals, complementary to discrete observations obtained by more traditional modes of sampling during brief encounters with a target species at aggregation sites or near fishing grounds (Sibert et al. 2006, Domeier \& Nasby-Lucas 2008). The power of an archival tag stems from its ability to measure both the external (e.g. depth, ambient water temperature, light level, salinity) and internal conditions (e.g. visceral temperature) of a tagged individual, and to relate these measurements to a place-in-time on Earth, i.e. a longitude and latitude. Although global positioning systems (GPS) and Argos satellites are ideal for providing fairly accurate positions, these methods are simply insufficient for most marine animals that remain submerged, out of the 
reach of satellite radio waves. Hence, it is necessary to infer positions from the data streams recorded by the tag sensors, particularly of light.

Light-based geolocation has been the primary means of positioning archival tags (Smith \& Goodman 1986, Wilson et al. 1992, Hill 1994) and can be carried out with the computation procedures provided by most tag manufacturers (Hill \& Braun 2001, Ekstrom 2004). However, the use of light-based position estimation methods suffers from a myriad of problems ranging from the behavior of the animals (e.g. deep diving or demersal lifestyle), over the poor ambient environmental conditions (e.g. turbid waters, cloud cover), to the lack of differences in day length around the equinoxes and bias introduced by the conversion between coordinate systems (Sibert et al. 2009). Longitude is usually more reliably estimated, with an error around $1^{\circ}$. In contrast, latitude estimates typically have errors from $2^{\circ}$ to $4^{\circ}$ (Schaefer \& Fuller 2006), and are capable of deviating up to $40^{\circ}$ from true positions (Musyl et al. 2001). These large errors could be mitigated through the use of improved algorithms, such as the templatefit method and the utilization of narrow-band blue light (Ekstrom 2004, 2007), or through the use of a holographic, cosine collector that increases the detection of diffused light during twilight (Qayum et al. 2007). Yet, as exciting as these new developments might be, the problem of light-based geolocation could benefit hugely by treatment in a robust statistical framework, as has been demonstrated by Nielsen \& Sibert (2007) with the use of the state-space model TrackIt. This model is unique in that it starts the estimation from the very outset of processing and uses the light data that has been recorded by the tag. It assumes an underlying movement model and estimates the track that best matches both the assumed model and the light time series. TrackIt does not reduce the light data to a time at which a solar altitude is assumed to be known (threshold limit; Hill \& Braun 2001), nor does it assume a specific relationship between solar altitude and light measurements (template-fit; Ekstrom 2007). This relationship is estimated empirically by the TrackIt model. Uncertainties are fully accounted for and propagated throughout, and the information gathered elsewhere in the track is available for estimating a current position.

Prior to TrackIt, most geolocation algorithms followed a disconnected, 1-way workflow, which used raw position estimates obtained from the manufacturer's processing software as inputs. Sea-surface temperature (SST)-matching is then conducted to constrain the search for latitude estimates within the areas of an appropriate SST field (Teo et al. 2004, Domeier et al. 2005). Previous model precursors of TrackIt also had to rely on the raw estimates as a starting point, despite their remarkable ability to improve position accuracy (Sibert et al. 2003), particularly when SST is used in combination with the state-space model (Nielsen et al. 2006, Lam et al. 2008). Instead of using SST as a patch to raw geolocation estimates, TrackIt incorporates SST into a single coherent model to estimate positions, founded on a set of much more reliable light-based geolocation estimates.

The current paper presents how SST is incorporated into TrackIt, and demonstrates how new observations can easily be added to the model. This flexibility of TrackIt is highly desirable given the emergence of novel sensor technologies, allowing the measurements of magnetic field properties, oxygen, and other chemical tracers. The present paper also addresses how satellite SST can affect the performance of TrackIt. Satellite SST products are growing in availability, usage, and sophistication, both in terms of the ability to resolve structures at very fine spatio-temporal scales and the developments in advanced assimilation and modeling. Although finer resolution SST products have the potential to further improve geolocation accuracy, it is extremely easy for researchers to get lost in a sea of product choices or the quest for the most detailed dataset. By comparing the most probable tracks from TrackIt to GPS and Argos tracks, our paper offers a handful of reference examples and practical guidelines for utilizing this model ${ }^{1}$.

\section{MATERIALS AND METHODS}

Model description. The purely light-based TrackIt model has been fully described in Nielsen \& Sibert (2007), so only a brief summary is presented here for completeness. Our focus is on the extension of this model with SST.

Solar event scanning procedure: A tag records light at a regular time interval (e.g. every minute), but for the purpose of geolocation, it is only the measurements taken during the time intervals around solar events (sunrise or sunset) that are useful (Nielsen \& Sibert 2007). For pop-up satellite archival tags (as in the following examples), these intervals are processed onboard within the tag, and only the processed information is returned. For archival tags, the entire record is available for retrieval, and the intervals must be identified by the user before the TrackIt model can be applied. Such a scanning algorithm has been suggested by Nielsen \& Sibert (2007) and has been implemented as part of the software.

\footnotetext{
$\overline{1}$ TrackIt can be downloaded at www.soest.hawaii.edu/tagdata/trackit/
} 
After the solar events have been identified, the light data consist of a vector of light readings around each solar event $l^{(i)}=\left(l_{1}^{(i)}, \ldots, l_{\mathrm{n}_{i}}^{(i)}\right)$ at times $\tau^{(i)}=\left(\tau_{1}^{(i)}, \ldots, \tau_{\mathrm{n}_{i}}^{(i)}\right)$. The mean time of each interval is denoted $\bar{t}_{i}=\operatorname{mean}\left(\tau^{(i)}\right)$.

Light-based model: TrackIt is a state-space model with an underlying movement model. The movement model assumed is a simple 2-dimensional random walk with semi-daily time steps $\bar{t}_{1}<\ldots<\bar{t}_{2 N}$. Here, $N$ is the number of days an animal is tagged.

For a given position in the underlying random walk, each observed light-vector $l^{(i)}$ is assumed to follow a multivariate normal distribution. The mean vector is calculated from (1) the solar altitude angles at that position and at the corresponding times $\tau^{(i)}$ (Meeus 1998) and (2) from an estimated relationship between the solar altitude angle and the light intensity (Fig. S1, available in the supplement at www.int-res.com/ articles/suppl/m419p071_supp.pdf). The covariance structure is designed to allow light measurements around the same solar event to be correlated, and this correlation is allowed to decrease as the time between measurements increases.

Including SST: Temperature is recorded in the tag with the same sampling frequency as the light readings, but only some temperature readings are near the surface. How frequent an animal visits the surface depends on the species. Assume that within the interval of the tag deployment it is possible to get estimates of sea-surface temperature $s s t_{1}, \ldots, s s t_{n_{S}}$ from the tag at times $S_{1}<\ldots<S_{n_{s}}$. To include these additional measurements at the correct times, the number of steps in the random walk is first increased to include both the observation times for the light data $\bar{t}_{1}<\ldots<\bar{t}_{2 N}$ and the observation times for the SST data $s s t_{1}, \ldots, s s t_{n_{s}}$. This new set of times is denoted $T_{1}<\ldots<T_{2 N+n_{s}}$. The random walk is otherwise defined as described by Nielsen \& Sibert (2007):

$$
\left(\begin{array}{c}
x_{T_{i}} \\
y_{T_{i}}
\end{array}\right)=\left(\begin{array}{l}
x_{T_{i-1}} \\
y_{T_{i-1}}
\end{array}\right)+\left(\begin{array}{l}
u \\
v
\end{array}\right) \Delta T_{i}+\eta_{i}, \quad i=1, \ldots,\left(2 N+n_{s}\right)
$$

Here, $(x, y)$ is the position in nautical miles (1 nautical mile $=1.852 \mathrm{~km}$ ) from a fixed point. The random part $\eta_{i}$ is assumed to be uncorrelated and follow a 2-dimensional normal distribution with a mean vector 0 and a covariance matrix $2 D \Delta T_{i} I_{2 \times 2}$. $D$ is a model parameter quantifying the diffusive movement component, and $(u, v)^{\prime}$ is a velocity vector describing the deterministic (advective) part of the movement pattern.

At each of the times $T_{i}$ in the random walk in Eq. (1), an observation is available (Fig. 1). In $2 N$ of the cases it is a vector of light measurements $l^{(i)}$ and a correspond- ing vector of measurement times $\tau^{(i)}$ around $T_{i}$, and the detailed likelihood formulation for these cases is described by Nielsen \& Sibert (2007). In the remaining cases $n_{S}$ the observation is a single SST measurement recorded by the tag. The equation for these observations is:

$$
\mathrm{SST}^{(i)}=\mathcal{S}\left(x_{T_{i^{\prime}}}, y_{T_{i^{\prime}}}, T_{i}, r\right)+b_{\mathrm{sst}}+\xi^{(i)}
$$

The function $\mathcal{S}$ gives the prediction of the SST at the position $\left(x_{T_{i^{\prime}}} y_{T_{i}}\right)$ at time $T_{i}$. The prediction is generated from satellite imagery by a weighted average of the satellite SST points within a radius $r$ from the position $\left(x_{T_{i}}, y_{T_{i}}\right)$. The weights are computed by $w_{j}=[1-$ $\left.\left(d_{j} / r\right)^{3}\right]^{3}$, where $d_{j}$ is the distance along the sphere of the $j^{\prime}$ th satellite SST point (within $r$ ) from target position $\left(x_{T_{i^{\prime}}} y_{T_{i}}\right)$. The model parameter $b_{\text {sst }}$ allows a systematic bias between the satellite SST and the tag SST. The measurement error $\xi^{(i)}$ is assumed to be normal and independent, $\xi^{(i)} \sim \mathcal{N}\left(0, \sigma_{\text {sst }}^{2}\right)$. SST-field observations on land are treated as missing observations, so no land temperatures are used. This means when a position approaches land, the gradient of SST, as returned by the $\mathcal{S}$ function, will gradually become zero, and the SST itself will become constant. This allows a smooth transition from water to land and means that land avoidance is not enforced by the model.

Double-tagging data. Four double-tagging datasets were used in the analysis. Three mako sharks Isurus oxyrinchus $(1901,1902,39322)$ were tagged with Wildlife Computers' pop-up satellite archival tags (PSAT) and smart position or temperature transmitting tags (SPOT), as part of Southwest Fisheries Science Center's shark survey program (D. Holts \& S. Kohin unpubl. data). The SPOT tag is a radio-telemetry tag that obtains positional fixes from the Argos satellite system. An accuracy flag, referred to as the location class (LC), is associated with each position. Only positions with known errors (i.e. LC 1, 2, and 3) were used. Errors for LC 1, 2, and 3 are 1000, 350 and $150 \mathrm{~m}$, respectively (see Royer \& Lutcavage 2008 for a more complete description of Argos error values). Despite the limitations on accuracy, it is assumed that

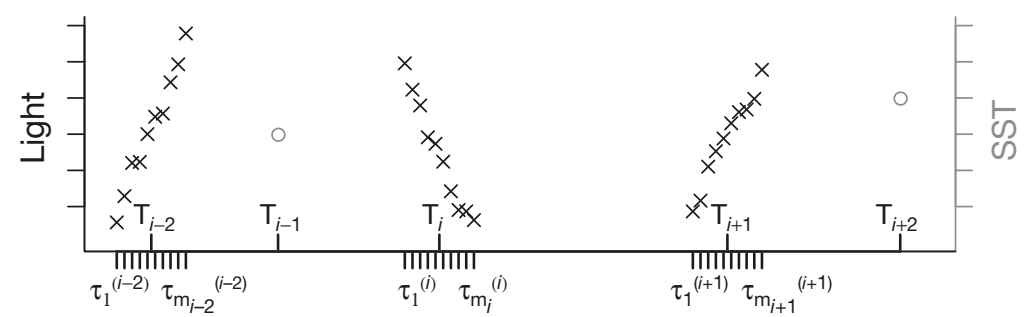

Fig. 1. Adding sea-surface temperature. The light-only model is extended by adding sea-surface temperature (SST) as additional observations. Light ( $\times$ ) and SST $(\bigcirc)$ observations are shown on the $y$-axis with time along the $x$-axis 
SPOT-Argos positions can provide informative track positions, which were used as a reference here. Additionally, a drifter buoy near Hawaii was fitted with a PSAT in September 2002 and set to pop-off after 9 mo (M. Musyl unpubl. data). The on-board GPS of the buoy provided the reference positions. Multiple positions available for a given day were averaged to give a single daily position. As a measure of accuracy, mean great-circle error (MGCE) and root-mean-square error (RMSE) were then calculated with the paired daily positions between the reference and estimated tracks.

Basic processing. None of the tags were recovered; therefore, all collected data were satellite-transmitted data summaries after tag pop-off. Transmitted data were processed with the manufacturer's software, which typically provided 9 to 12 light measurements (taken 8 min apart) around a solar event (sunrise or sunset). Since the full time series of light data was not available, no solar event scanning procedure was carried out, and the transmitted light data were used as is. Depth correction of the light data was programmed by the manufacturer to be carried out on-board, and, consequently, users had no control over how it was done. Tag-recorded SSTs were obtained from the Wildlife Computers' AMP software output ('locations' worksheet). Since the 3 mako sharks and the drifter buoy were often found at or near the surface, all the daily SST values were recorded at $0 \mathrm{~m}$, eliminating the need to define arbitrarily a depth for the surface layer in deriving SSTs.

Satellite SST imagery. Four satellite SST products covering a range of spatio-temporal resolutions were used in the comparative analysis. The coarsest resolution product is the NCEP Reynolds optimally interpolated (OI) SST, which is derived from the Pathfinder satellite's advanced very high resolution radiometer (AVHRR) and in situ measurements of SST (Reynolds \& Smith 1994). Interpolation eliminates data gaps due to cloud cover and provides a continuous $1^{\circ}$ by $1^{\circ}$ globally gridded dataset. The 8 day composite was used as the default SST imagery for running the model.

The 3 higher resolution products were:

1. MODIS Aqua SST: the moderate resolution imaging spectroradiometer (MODIS) is flown on NASA's Aqua satellite, and its data are processed by the Ocean Biology Processing Group (http://oceancolor.gsfc.nasa.gov/). The Level 3 global coverage $8 \mathrm{~d}$ composite was used, covering a spatial grid of $0.05^{\circ}$ by $0.05^{\circ}(\sim 4 \mathrm{~km})$.

2. CoastWatch blended: the NOAA CoastWatch experimental blended SST is derived from both microwave and infrared sensors carried on multiple platforms (NOAA 2007). The advantage of including microwave sensors is that they can acquire measurements in the presence of clouds, although their coarser spatial resolution may be considered inadequate for coastal applications. This shortcoming is addressed by supplementing measurements from multiple infrared platforms. Data from multiple sources were remapped to an equal angle grid of $0.1^{\circ}$ by $0.1^{\circ}(\sim 11 \mathrm{~km})$, and simple arithmetic means were calculated for each grid square. The running 5 day composites were available daily through the NOAA BloomWatch 360 website (http://coastwatch.pfeg.noaa.gov/coastwatch/ CWBrowserWW360.jsp).

3. NOAA OI SST: the NOAA OI $0.25^{\circ}$ daily SST analysis (Reynolds et al. 2007; www.ncdc.noaa.gov/oa/ climate/research/sst/oi-daily.php) is one of the operational Level 4 products of the group for high resolution sea surface temperature (GHRSST; www.ghrsst-pp. org/). GHRSST is an effort to provide uniformly processed, global, high-resolution satellite SST products, and to bring data providers and users together in advancing the field of remotely sensed SST. While a microwave-blended version is available, the AVHRRonly (Version 1) dataset was used in the analysis because of its extended temporal coverage from 1985 to the present. This product explicitly follows the SST definitions of GHRSST (www.ghrsst-pp.org/SSTDefinitions.html) and provides a foundation SST (at the base of the upper ocean, $\sim 10 \mathrm{~m}$ ) free of diurnal influences. It also provides the bias and standard deviation errors through the single sensor error statistics (SSES) for every grid square. This product is offered daily at a spatial grid of $0.25^{\circ}$ by $0.25^{\circ}(\sim 25 \mathrm{~km})$.

To reduce the computational demand for running TrackIt, high-resolution SST images were downloaded once every $8 \mathrm{~d}$, even if a product was available daily. A single downloaded image would be re-used as the satellite SST field for the subsequent days within an $8 \mathrm{~d}$ window. No interpolation or other manipulation was performed prior to running the model.

\section{RESULTS}

\section{General features of incorporating SST}

Incorporating SST into TrackIt improves the overall accuracy of position estimates (Table 1 ; MGCE) and reduces the confidence regions. Figs. 2 to 5 show comparisons of tracks from the different models, for 3 sharks and a drifter buoy. Errors in latitude estimates from the light-only model can sometimes exceed $5^{\circ}$ (Fig. 2, October; Fig. 3, August), and are not confined to coastal regions (Fig. 5, April). This is reflected by the widening of the confidence regions during those periods of the light-only model. Moreover, a consistent pattern is evident from the latitude standard deviation (Fig. 6), where the standard deviation for the light-only models is much higher around the equinoxes. During such periods, adding SST can reduce the latitude stan- 
Table 1. Selected parameter and accuracy estimates for the models; $\log L$ is the negative $\log$-likelihood value of a model (the smaller the value, the better is a model fit), radius is in nautical miles; $D$ is in square nautical miles per day, $b_{\text {st }}$ and $\sigma_{\text {sst }}^{2}$ in degrees Celsius. The models are: light only, light with Reynolds $1^{\circ}$ OI SST, light with NOAA $0.25^{\circ}$ OI SST Version 1 AVHRR-only or NASA MODIS Aqua $0.05^{\circ} 8 \mathrm{~d}$ composite SST, and light with CoastWatch blended $0.1^{\circ}$ experimental SST. For the complete list of parameter estimates, refer to Table S1 (available in the supplement at www.int-res.com/articles/suppl/419p071_supp.pdf). Accuracy estimates were calculated as the mean great-circle error (MGCE) \pm standard deviation (SD) in nautical miles, and the root-meansquare error (RMSE) was determined for longitude (lon) and latitude (lat) in degrees. The number of Argos or GPS positions avail-

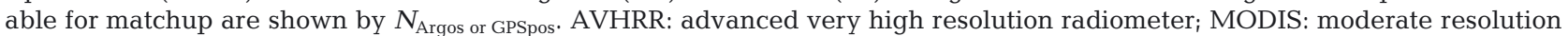
imaging spectroradiometer; NASA: National Aeronautics and Space Administration; NOAA: National Oceanic and

Atmospheric Administration; OI: optimum interpolation; SST: sea-surface temperature; ${ }^{*}$ : not estimated; NA: not applicable

\begin{tabular}{|c|c|c|c|c|c|c|c|c|c|}
\hline & \multirow[b]{2}{*}{$\log L$} & \multicolumn{3}{|c|}{ - Model parameters } & \multirow[b]{2}{*}{$\sigma_{\text {sst }}^{2}$} & \multirow[b]{2}{*}{$\begin{array}{c}\text { MGCE } \\
\pm \mathrm{SD}\end{array}$} & \multicolumn{2}{|c|}{ Accuracy estimates } & \multirow[b]{2}{*}{$\begin{array}{c}N_{\text {Argos }} \text { or } \\
N_{\text {GPSpos }}\end{array}$} \\
\hline & & $D$ & Radius & $b_{\text {sst }}$ & & & $\mathrm{RMSE}_{\text {lon }}$ & $\mathrm{RMSE}_{\text {lat }}$ & \\
\hline Mako 1901 & & & & & & & & & 124 \\
\hline Light only & 7851 & 505.02 & NA & NA & NA & $140 \pm 108$ & 0.49 & 2.93 & \\
\hline Light + Reynolds SST & 8085 & 383.48 & 88.37 & -1.14 & 0.51 & $102 \pm 72$ & 0.50 & 2.05 & \\
\hline Light + NOAA OI SST & 8111 & 320.33 & 74.79 & -1.01 & 0.78 & $93 \pm 62$ & 0.47 & 1.82 & \\
\hline Light + CoastWatch blended & 8100 & 309.86 & 92.84 & -1.27 & 0.57 & $94 \pm 73$ & 0.59 & 1.91 & \\
\hline Mako 1902 & & & & & & & & & 78 \\
\hline Light only & 7105 & 726.02 & NA & NA & NA & $153 \pm 109$ & 0.53 & 3.11 & \\
\hline Light + Reynolds SST & 7346 & 952.07 & 370.77 & -2.95 & 0.64 & $109 \pm 60$ & 0.62 & 2.01 & \\
\hline Light + NOAA OI SST & 7359 & 835.88 & 860.81 & -2.94 & 1.42 & $91 \pm 56$ & 0.51 & 1.74 & \\
\hline Light + CoastWatch blended & 7352 & 967.95 & 240.09 & -2.80 & 0.67 & $116 \pm 64$ & 0.68 & 2.14 & \\
\hline Mako 39322 & & & & & & & & & 91 \\
\hline Light only & 5839 & 519.84 & NA & NA & NA & $76 \pm 46$ & 1.05 & 1.19 & \\
\hline Light + Reynolds SST & 6052 & 326.78 & 162.12 & -0.80 & 0.41 & $71 \pm 32$ & 0.90 & 1.05 & \\
\hline Light + NOAA OI SST & 6076 & 630.66 & 649.31 & -0.98 & 1.41 & $105 \pm 79$ & 1.02 & 2.02 & \\
\hline Light + CoastWatch blended & 6075 & 289.53 & $200^{*}$ & $0^{*}$ & 0.70 & $80 \pm 52$ & 0.87 & 1.42 & \\
\hline Drifter & & & & & & & & & 165 \\
\hline Light only & 9964 & 472.90 & NA & NA & NA & $158 \pm 81$ & 0.36 & 2.95 & \\
\hline Light + Reynolds SST & 10191 & 276.57 & 1200 & 1.90 & 0.50 & $71 \pm 52$ & 0.32 & 1.44 & \\
\hline Light + MODIS Aqua & 10326 & $200^{*}$ & $80^{*}$ & $0.6^{*}$ & $0.38^{*}$ & $71 \pm 58$ & 0.30 & 1.51 & \\
\hline Light + CoastWatch blended & 10187 & 202.84 & $80^{*}$ & 0.61 & 0.38 & $51 \pm 32$ & 0.31 & 0.97 & \\
\hline
\end{tabular}

dard deviation drastically. It appears that even with infrequent sampling of once per day, SST observations can improve geolocation estimates and shrink confidence regions.

Longitude estimates (RMSE $\sim 0.3$ to $1^{\circ}$ ) are generally more reliable than those of latitude (RMSE $\sim 1$ to $3^{\circ}$ ), which is common to all light-based geolocation methods. At present, TrackIt does not implement a land or bathymetric mask and may sometimes place position estimates on land when applied near the coast. Land thus provides an additional means for evaluating the model results. Light-only models can be affected by degraded light measurements in high-turbidity, productive coastal waters, placing track estimates on land (Fig. 4A). By adding SST to the model, the low-resolution Reynolds SST model eliminates the land displacement, corrects the longitude estimates (Fig. 4B), and provides latitude estimates very similar to those of the light-only model.

\section{Satellite SST imagery resolution}

Resolution of SST imagery does not have marked impacts on model performance (Fig. 7). The lowest resolu- tion Reynolds $1^{\circ}$ product produces track estimates similar to those of higher resolution products that are at least 4 times better resolved (e.g. Figs. 2 \& 3). Results here show that low-resolution satellite SST data are adequate for the purpose of geolocation, at least when using the TrackIt model. This is consistent with a similar finding in another state-space Kalman filter model employing SST-matching (Lam et al. 2008).

Besides the resolution of the SST imagery, the smoothing radius $(r)$ is an important indicator of how the model utilizes the satellite imagery. The smoothing radius was estimated whenever possible (i.e. model converged; Table 1). A small radius uses a more confined neighborhood in calculating the average SST value for a given longitude-latitude position. The tracks are very similar when all 3 SST-inclusive models were estimated using a small radius $(<100$ nautical miles; Fig. 2). It is often expected that the use of higher resolution imagery should lower the smoothing radius, but this is not necessarily the case. A very low smoothing radius can retain observation noise in the SST field and lead to unstable estimates. Trade-offs were made in fitting various model parameters, including the radius, in order to obtain numerical minimization of the likelihood function. 

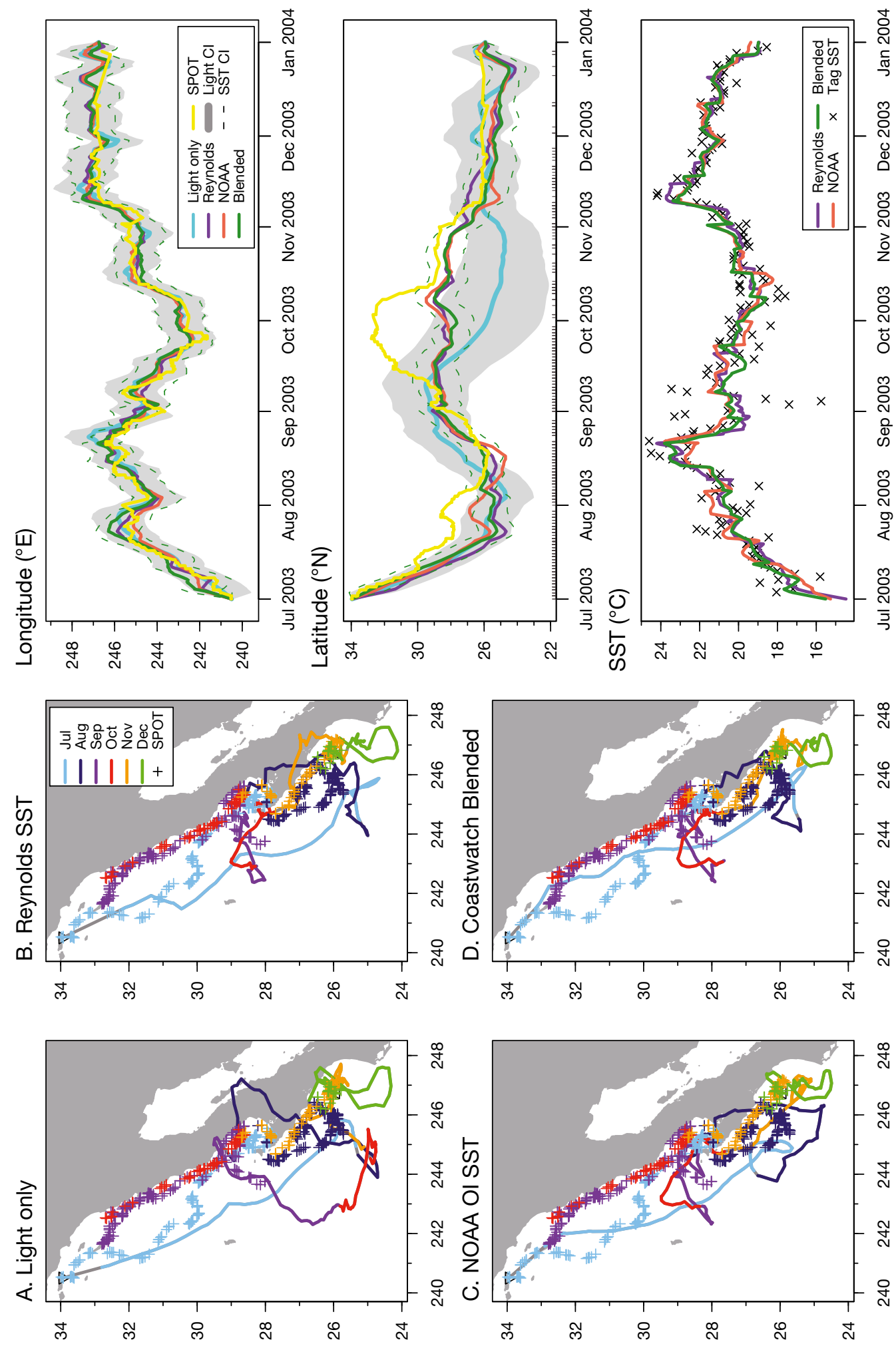

Latitude $\left({ }^{\circ} \mathrm{N}\right)$

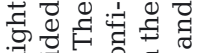

ช

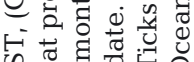

की

○ 웡 क्व

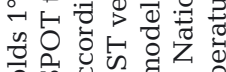

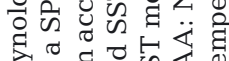

ब्व वृ क्ष

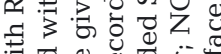

广す

등

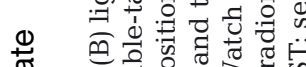

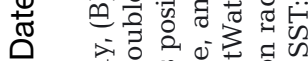

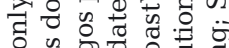

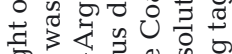

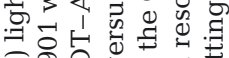

画穴

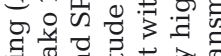

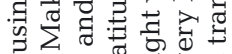

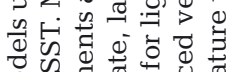

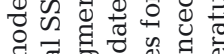

द्व त्ँच क्षे

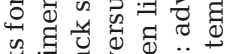

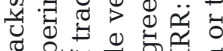

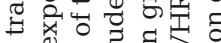

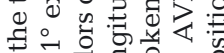

उ० 웡영

岳焉 d

可过记

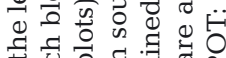

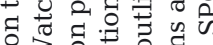

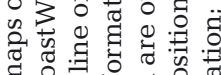

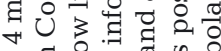

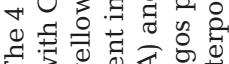

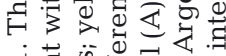

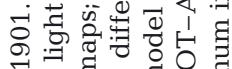

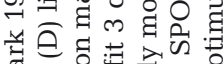

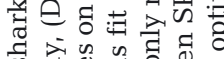

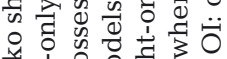

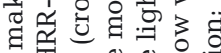

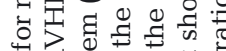

n 4 w

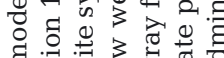

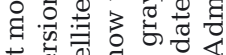

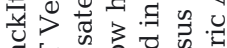

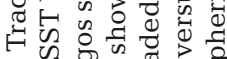

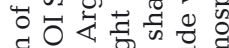

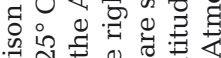

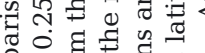

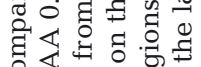

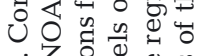

i Z

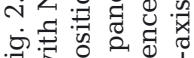




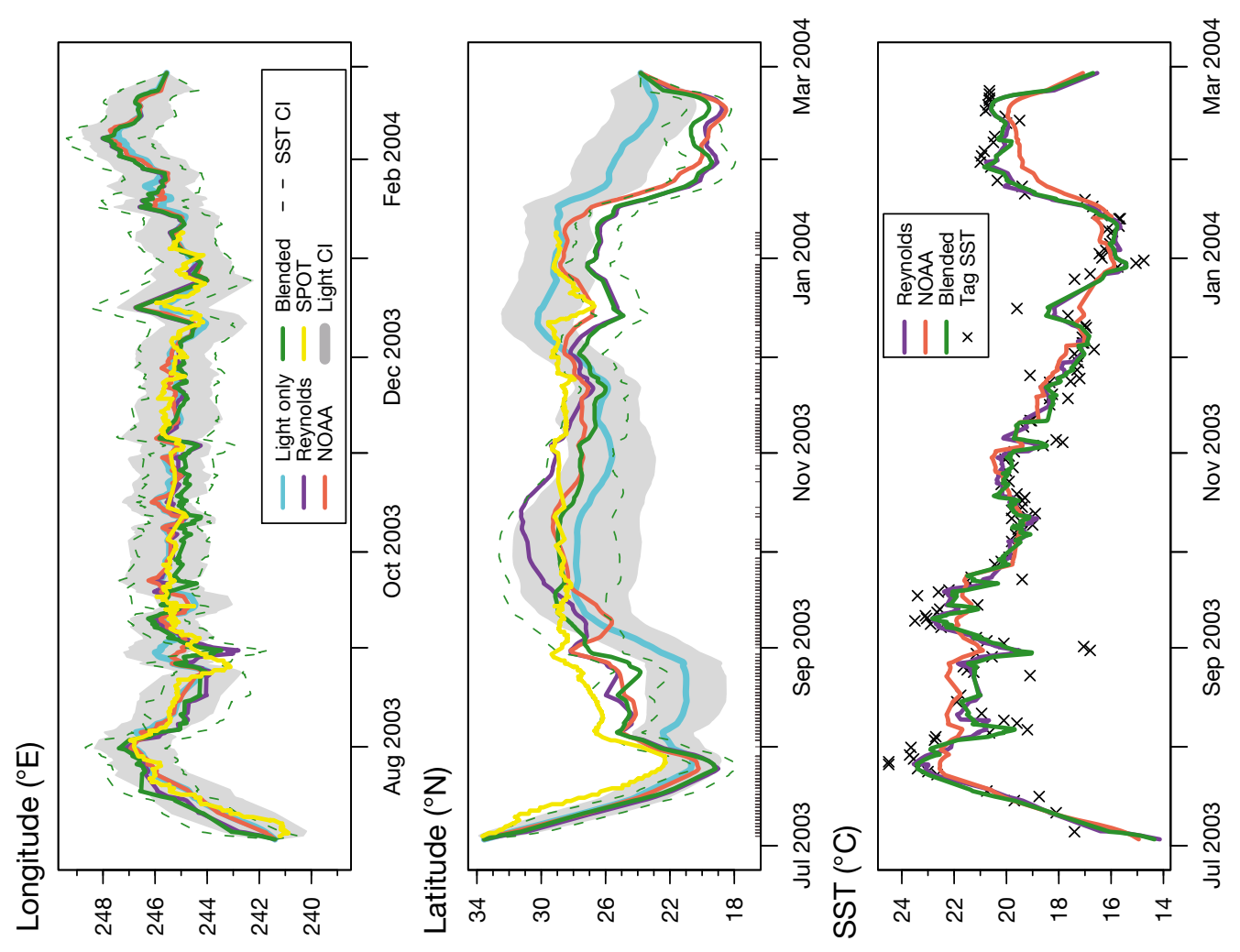

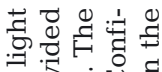

Uิ

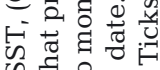

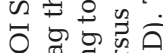

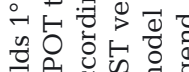

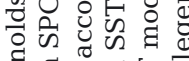

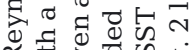

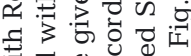

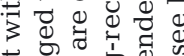

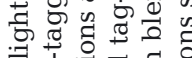

要娄

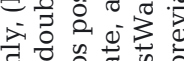

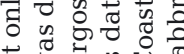

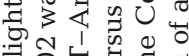

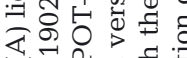

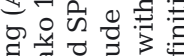

要党

要

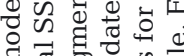

a

웜

政

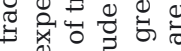

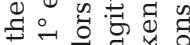

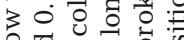

ज़

훙

o

둥

b

啶

to $\neq 0$

专远远

성 츨

诸家

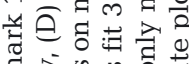

क्ष

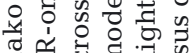

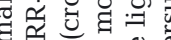

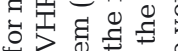

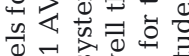

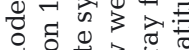

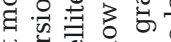

这政

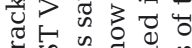

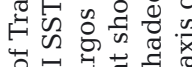

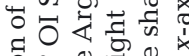

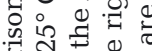

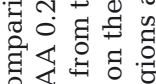

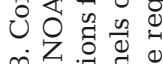

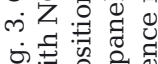

Latitude $\left({ }^{\circ} \mathrm{N}\right)$ 

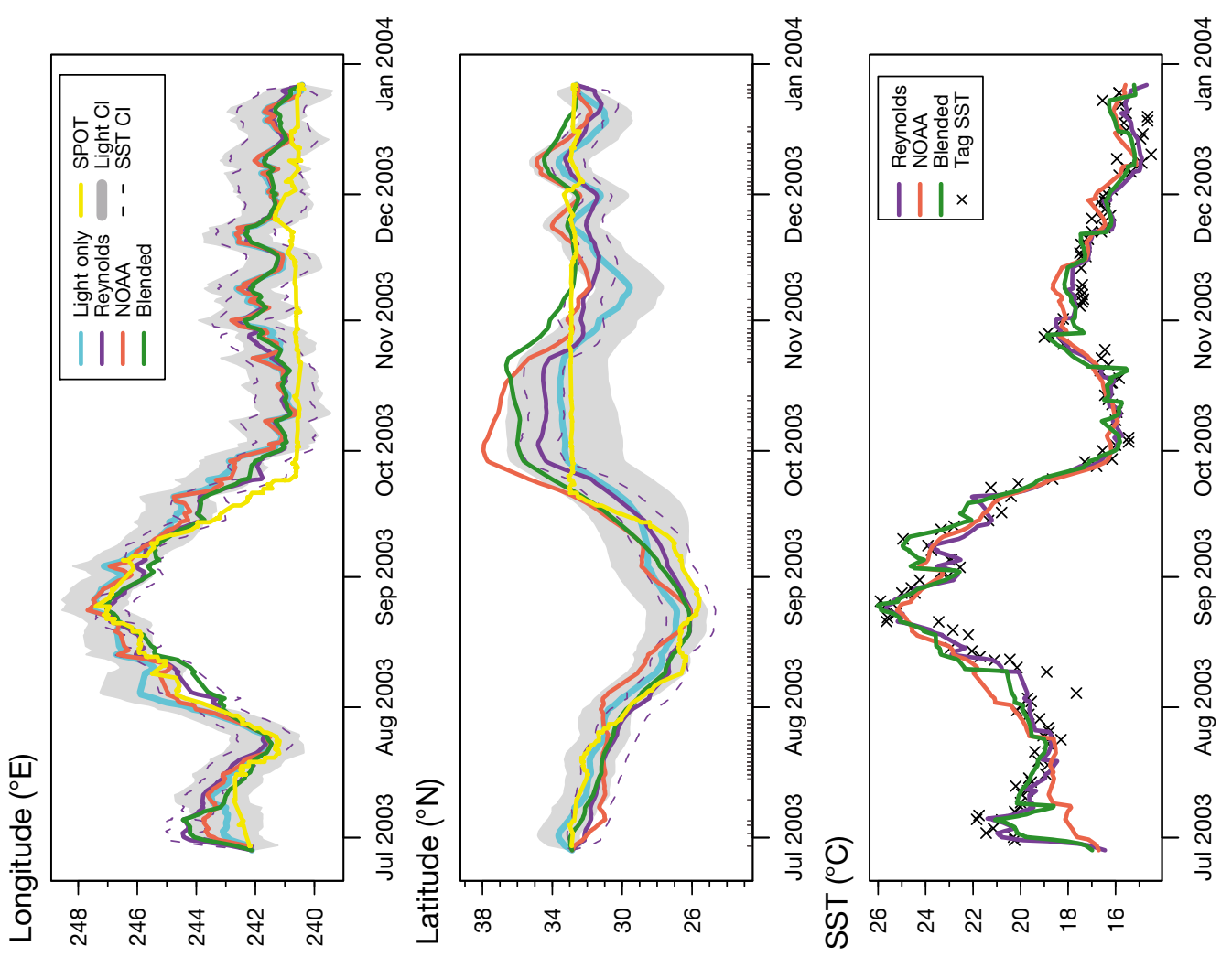

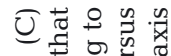

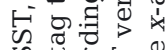

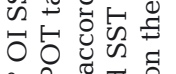

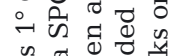

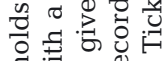

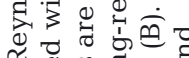

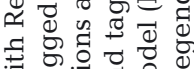

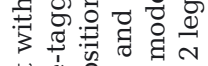

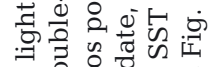

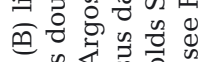

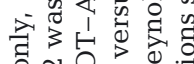

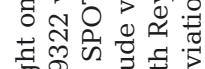

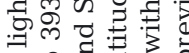

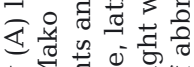

就苞吾:

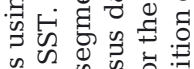

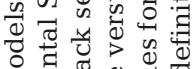

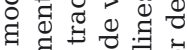

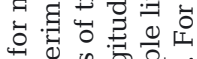

幽 :

0.

\& 0 .

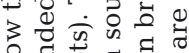
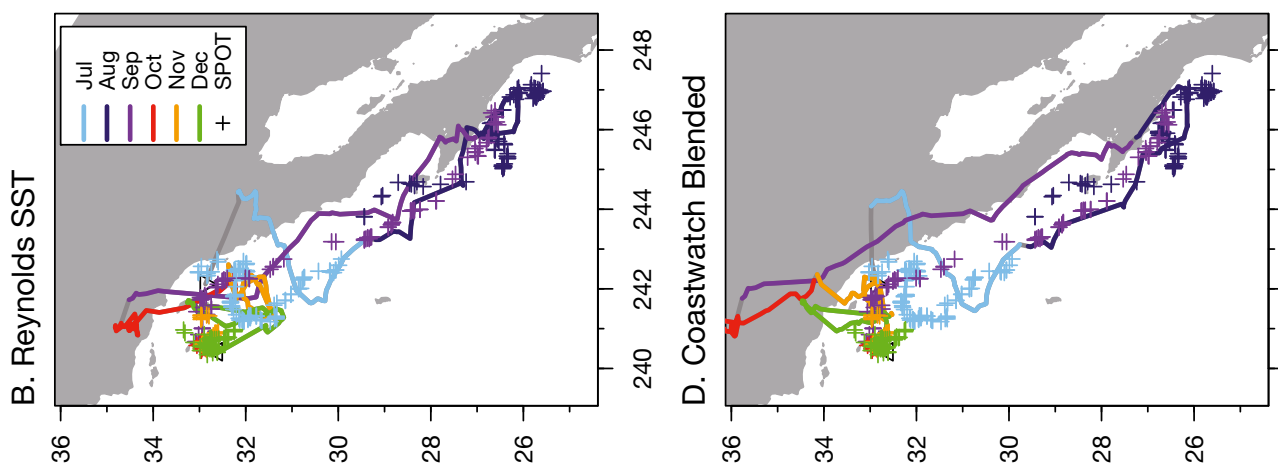

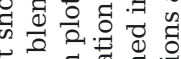

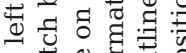

Q

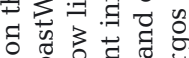

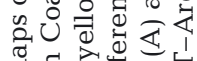

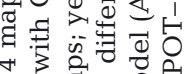

+ उ्वेग

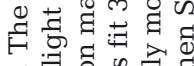

ง $0 \frac{n}{8}$ 过

कू

范

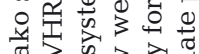

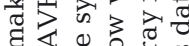

혀월

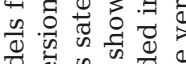

ठ

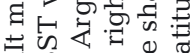

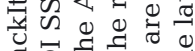

记

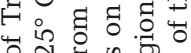

ᄃ 0 业

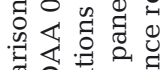

苛问 $m$

매욜

- 3 .

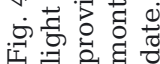



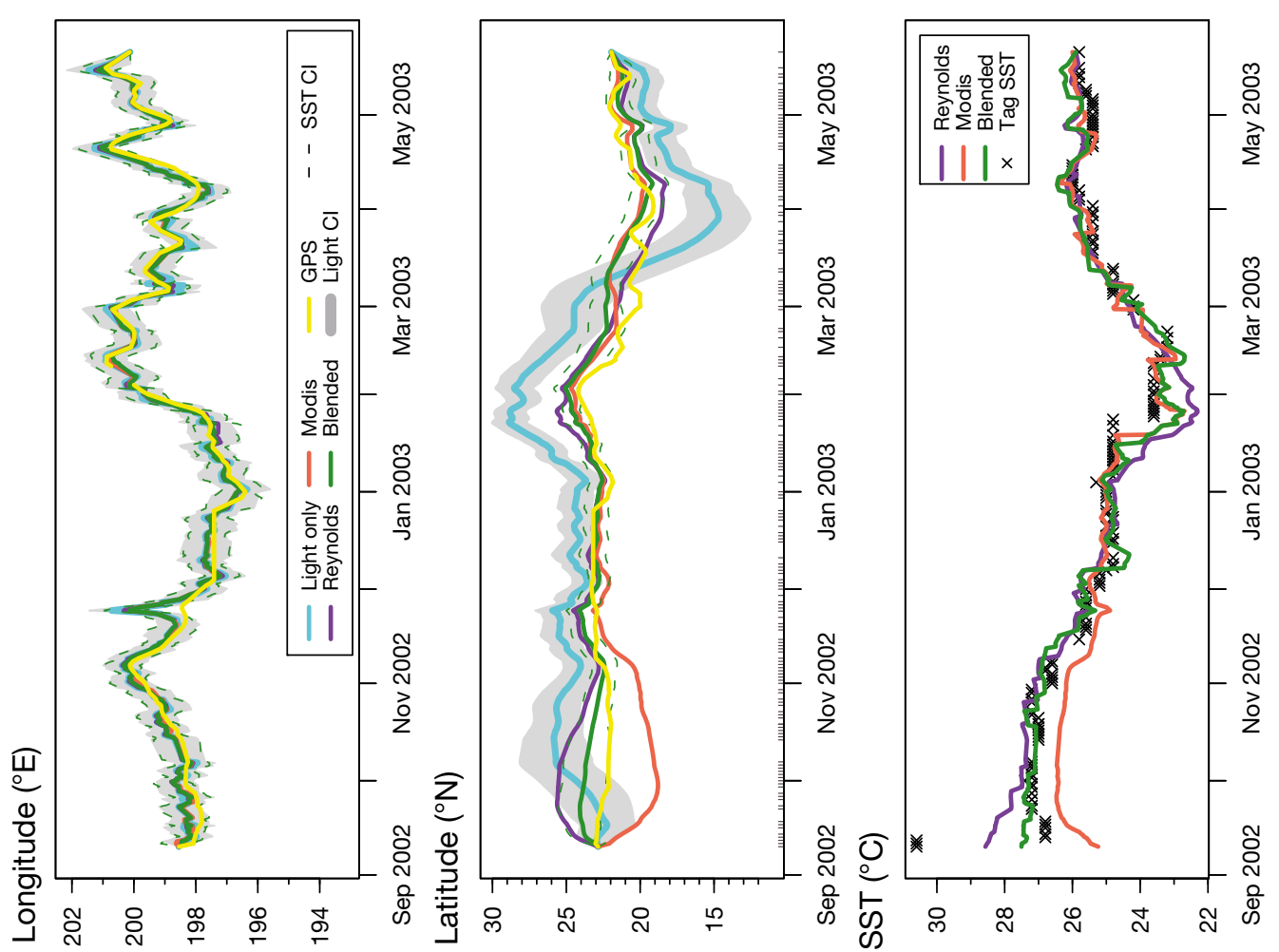

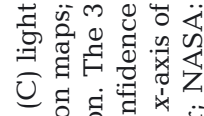

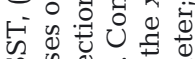

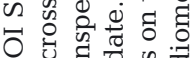

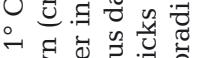

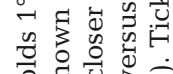

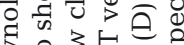

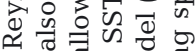

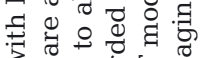

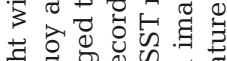

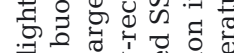

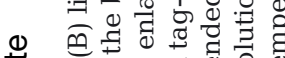

更 ปี ปี

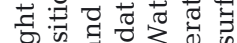

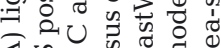

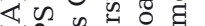

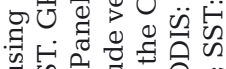

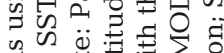

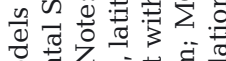

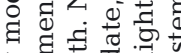

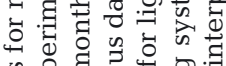

जी

व.

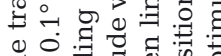

¿

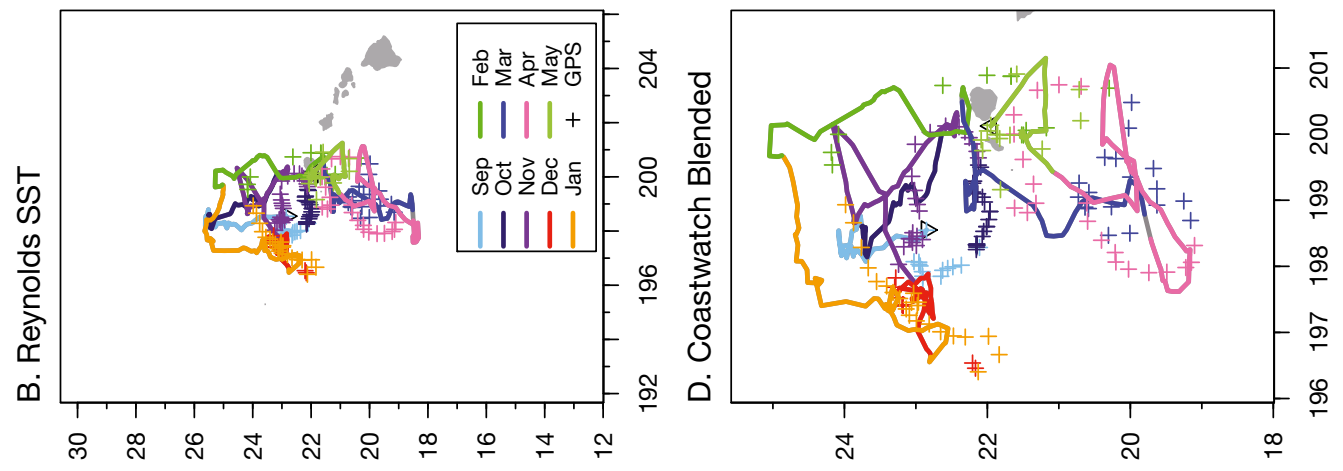

उठ듀

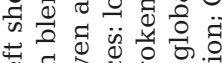

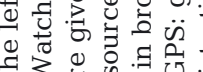

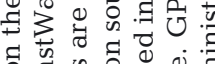

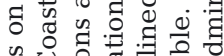

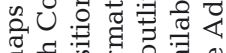

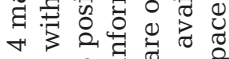

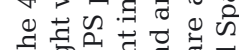

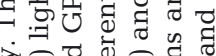

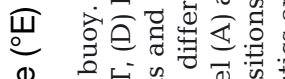

o

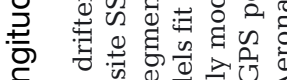

ర్ ठ

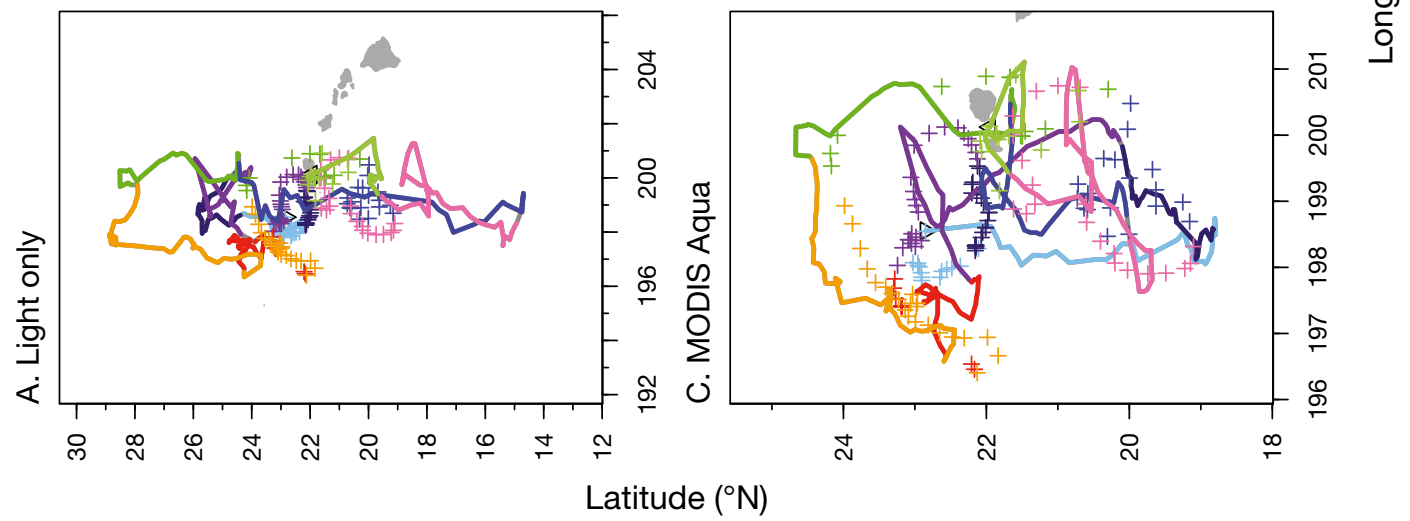

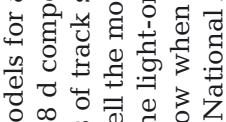

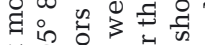

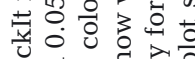

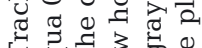

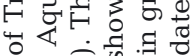

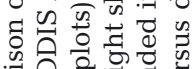

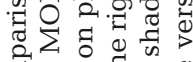

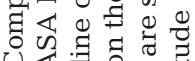

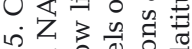

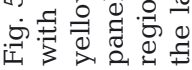



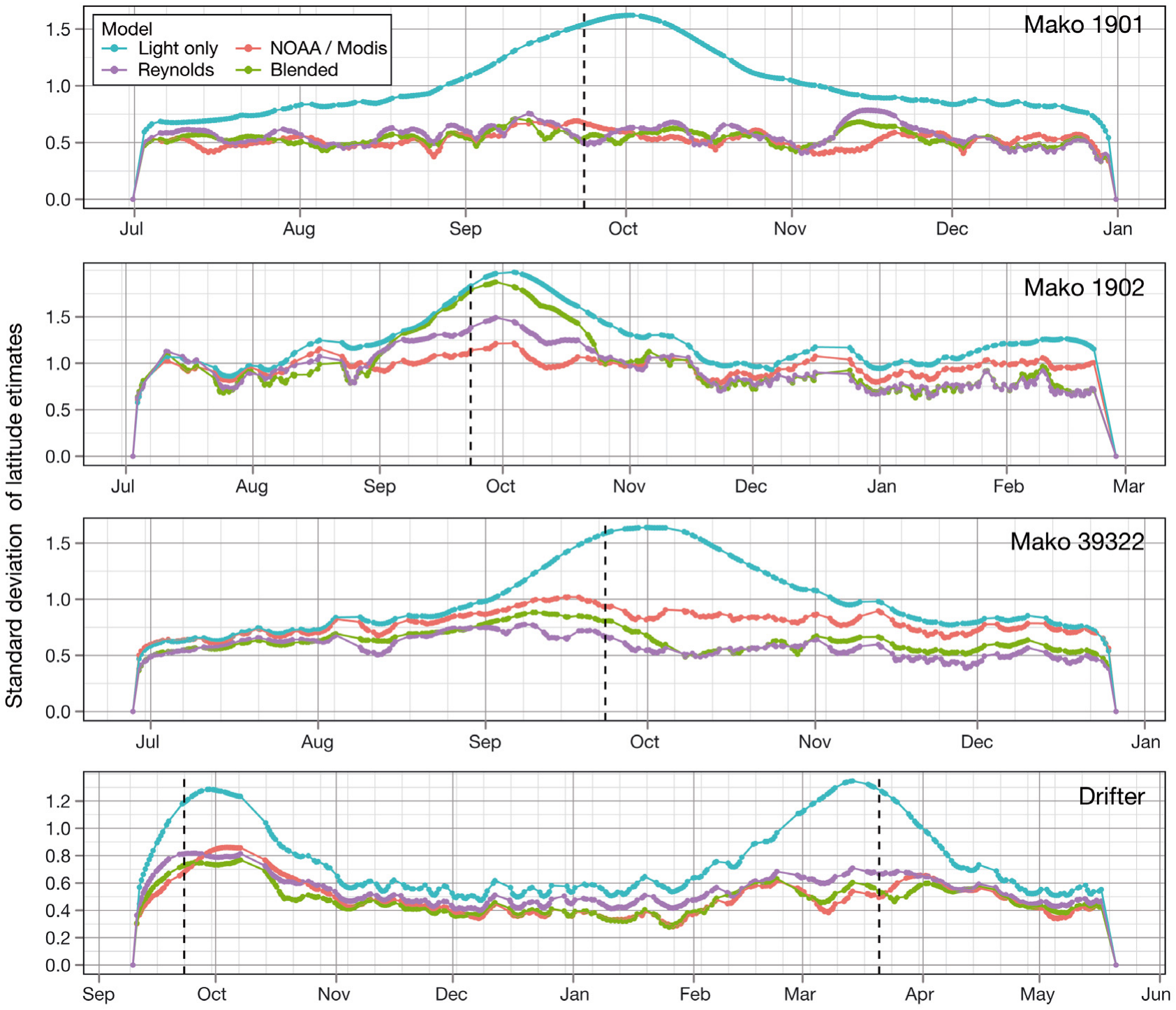

Fig. 6. Estimated standard deviation of latitude from TrackIt models. The models are: (A) light only, (B) light with Reynolds $1^{\circ}$ OI SST, (C) light with NOAA $0.25^{\circ}$ OI SST Version 1 AVHRR-only or NASA MODIS Aqua $0.05^{\circ} 8 \mathrm{~d}$ composite SST, and (D) light with CoastWatch blended $0.1^{\circ}$ experimental SST. Broken vertical lines indicate the times of equinox. Note: the $y$-axis range is different between plots

A larger radius may allow more room for latitude misplacement. This is most clearly seen in the maps of Mako 39322, where the October track segment ventured more inland when the low-resolution Reynolds SST (Fig. 4B, $r$ = 162 nautical miles) was replaced with the higher resolution NOAA OI SST (Fig. 4C, $r=649$ nautical miles). This potential downside of having to smooth satellite imagery is also evident by comparing the October track segments between the light-only model (Fig. 4A) and the light with the Reynolds SST model (Fig. 4B). It is also complicated by the lack of any useful trends in the October temperatures for SST-matching, a feature that is explored in the following subsection.

\section{Trends in the tag-recorded SST}

The addition of SST to TrackIt improves geolocation accuracy the most when there are marked trends in the tag-recorded SST data (Fig. 5). Conversely, adding SST degrades the accuracy when tagrecorded SSTs remain uniform for an extended period of time (Fig. 4, October), during which time the lightonly model performs far better than any other model. Even when there is a wide spread in the tag-recorded SSTs, SST-matching can improve geolocation estimates if there is a noteable trend over time (Fig. 2, late-September). 

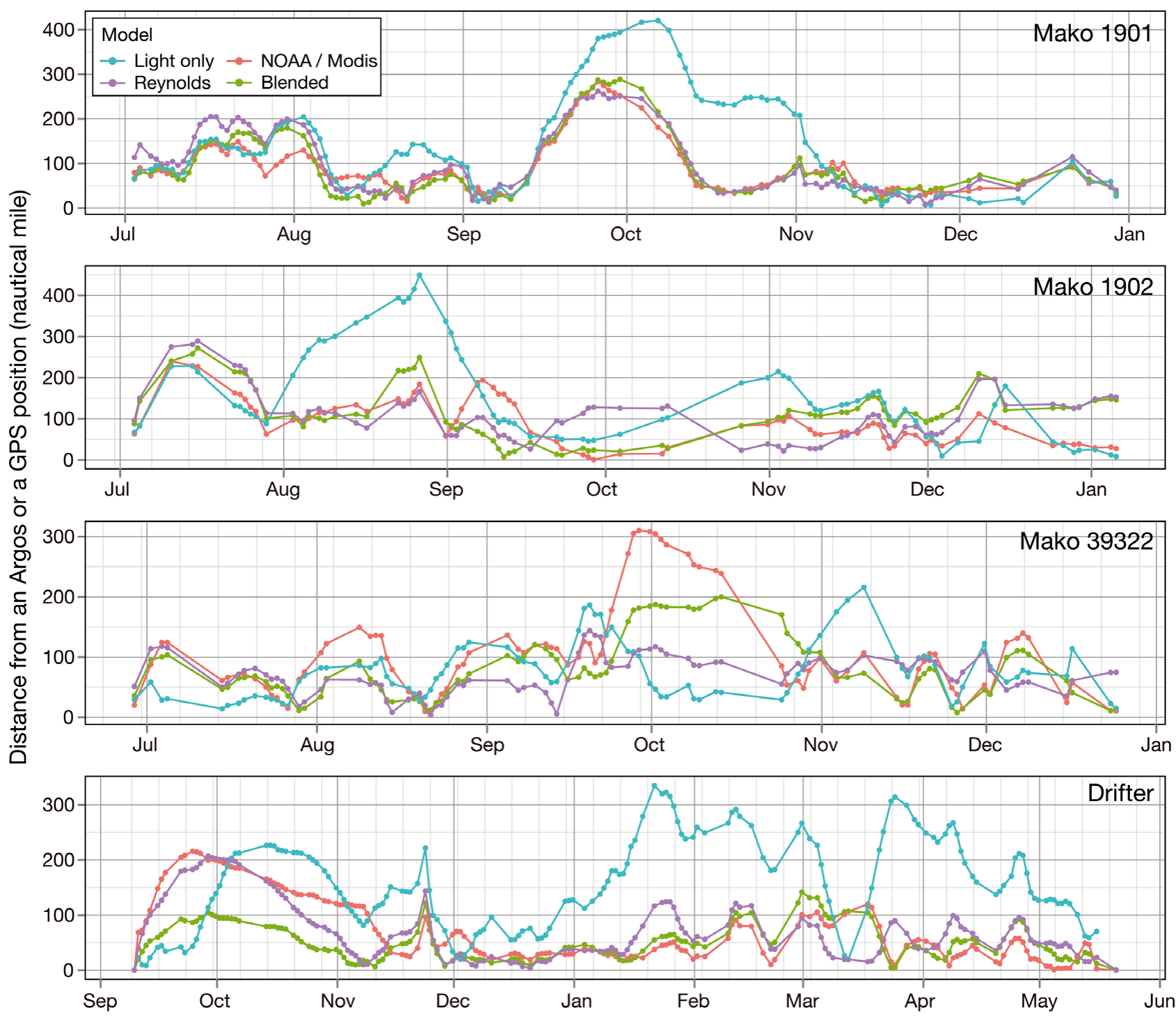

Fig. 7. Great-circle distance (in nautical miles) between a TrackIt position and an Argos or GPS position. Paired positions are available daily. The models are: light only, light with Reynolds $1^{\circ}$ OI SST, light with NOAA $0.25^{\circ}$ OI SST Version 1 AVHRR-only or NASA MODIS Aqua $0.05^{\circ} 8 \mathrm{~d}$ composite SST, and light with CoastWatch blended $0.1^{\circ}$ experimental SST. Note: the $y$-axis range is different between plots

The SST recorded by a tag is a function of both regional oceanography and movement activity. SST-matching is most effective when the temperature signal in an area is spatially stratified and allows, for instance, the tracking of an animal that moves along a SST isotherm. On the other hand, a trend in tag SST can be available for matching, either through the presence of strong temperature gradients in an area (particularly along the latitudinal axis) or the transversing of water bodies with different temperature signatures when an animal moves from one place to another. For the latter case, the light-only position estimates alone should reveal whether an animal remains localized within a region. It is not important to identify the exact cause for an observed SST trend, as this differs from case to case. For example, a downward and, then, an upward trend were observed with the buoy passively drifting in a rather homogenous SST environment $\left(\sim 22\right.$ to $\left.28^{\circ} \mathrm{C}\right)$ near Hawaiian waters (Fig. 5), while for the mako sharks that remained near the California coast (Fig. 2, mid-November; Fig. 4, mid-October), a trend in tag SST was established when colder water moved in or out of the Southern California Bight. 


\section{DISCUSSION}

The incorporation of SST in TrackIt presents a unified and generalized framework for assimilating new types of observations to the light-based geolocation model. Double-tagging examples in the present paper have demonstrated that TrackIt with SST provides improved movement estimation to within 100 nautical miles, on average, from satellite radio telemetry methods in both the coastal environment and the open ocean. Furthermore, the current paper has identified scenarios in which the model could under-perform and has indicated the possible causes of errors.

Despite the utility of TrackIt, it has a few limitations at present, such as keeping the model simple by assuming Gaussian error distributions, not avoiding land explicitly, and using a random walk with the Kalman filter (see Thygesen \& Nielsen [2009] for an insightful exploration of the implications of this filter choice). Future application of other filtering techniques, such as hidden Markov models (Thygesen et al. 2009), would allow the combination of the data and model treatment of TrackIt with land masks, but that is beyond the scope of the present paper. Several hardware and sampling-related artifacts are not handled by TrackIt either, but can often be addressed with careful exploration analyses and preprocessing prior to running the model; this includes the correction of clock or depth drift, a definition of the surface layer depth for deriving tag-measured SST values, and the appropriate compensation of light measurements made at depths (TrackIt comes with a R function ${ }^{2}$, two.layer.depth.corr following Ekstrom 2002).

The statistical state-space nature of TrackIt provides a transparent means to evaluate the model performance. Error structure, such as the standard deviation of latitude estimates (Fig. 6), allows the visual inspection of how the model behaves during various times of the year and with different sources of inputs. The confidence regions also give an impression of the uncertainty of track estimates and are accessible through a simple command in the TrackIt R-package, e.g. plot(track, $c i=$ TRUE). The SST versus date-time plot is another diagnostic method for examining whether trends in tag-measured SSTs exist for satellite SSTs to be useful in improving the position estimates. Since TrackIt is primarily designed for open ocean applications and does not utilize land masks, a model yielding solutions with a higher proportion of points on land may be deemed less reliable.

$\underline{2} \mathrm{R}$ Foundation for Statistical Computing, Vienna, Austria (www.r-project.org)
The ability to run models with different satellite SST products is an excellent way to evaluate performance. Similar to the information presented in this paper, one can compare a light-only model with several light plus SST models. It is reassuring when the various SST models arrive at very similar solutions (e.g. Fig. 5, December and later). Conversely, one becomes more cautious when tracks for different models are divergent (e.g. Fig. 5, September to November). At other times, a systematic pattern can be seen as the resolution of satellite SST products increases (Fig. 4, October), which may indicate the smoothing of highresolution SST products can be problematic.

A careful evaluation of such signatures can be beneficial for understanding model performance. While one may be inclined to bypass or limit the timedemanding task of running multiple models, positional estimates are fundamental to the utility of electronic tagging data in ecological applications. Improved confidence in tracks via such comparative, optimal model selection is appropriate given the high cost of tagging operations and the perceived utility of tag data for fisheries management.

\section{Understanding and making trade-offs}

In selecting the 'best' estimated track, it is essential to consider the regional oceanography (e.g. coastal upwelling) and possible animal movement behavior (e.g. localized feeding) and to compare multiple models. Trade-offs are often required in the modeling process. For example, SST-matching helps to keep the light-only estimates off land in the case of mako shark 39322 (Fig. 4A,B), but artifacts from having a larger smoothing radius begin to show up when higher resolution SST products are used. This suggests that selecting the low-resolution Reynolds SST model is a good compromise. A model's negative log-likelihood (Table $1 ; \log L$ ) provides a means to compare different models. Indeed, in this example, the Reynolds SST model also has the lowest $\log L$ value among all SST models and further supports its final selection.

Another trade-off is that model convergence is required for using TrackIt, and sometimes it is necessary to simplify the model for that to occur. This involves keeping some parameters fixed (see TrackIt R-package documentation; e.g. rad.ph $=-1$ ) and providing better initial parameter estimates. It is an iterative process of first running a simplified model that converges and then feeding the resulting parameter estimates back as initial values for a more complex model. Again, the negative $\log$-likelihood $(\log L)$ value can be used to evaluate whether the complex model is justified. Under normal circumstances, model convergence is not hard 
to obtain, so this strategy only applies to the trickier cases in which model convergence cannot be obtained with the default initiation values of TrackIt.

\section{Choosing a satellite SST product}

SST is one of the best-characterized variables in satellite remote sensing. Many SST products and oceancirculation model outputs are available from numerous sources. Faced with this broad selection of SST products available for geolocating tags, researchers are very much challenged by having to select the appropriate SST product. As new, ultra-high-resolution SST products (1 to $4 \mathrm{~km}$ ) become available, this challenge will only become more prominent.

Understanding of the SST product being used is crucial, especially when moving towards utilizing higher and higher resolution products. Selecting a suitable product depends on the specific geographic settings and oceanographic applications. For example, infrared products are more resolved than microwave products in coastal regions during cloud-free days, and can better capture gradients in the SST field. Another example is the issue of diurnal variability of SST, where light winds and strong sunlight conditions create a stable warm surface layer that can differ diurnally by as much as 5 Kelvin $\left(=5^{\circ} \mathrm{C}\right)$ in the extreme cases (Gentemann et al. 2008). Both satellite and tag observations of SST can be sensitive to this variability. Since the handling of SST in TrackIt is rather basic (e.g. 1 daily SST; smoothing), users may want to exercise more control by preparing a customized set of SST data prior to running the model.

The present paper shows that low-resolution SST products are adequate for the purpose of geolocation. Standard deviation in latitude estimates is often among the lowest for models using Reynolds SST (Fig. 6). Moreover, computation time is much shorter for lowresolution SST models, and convergence is often easier to obtain. As a recommendation, one can run TrackIt with low-resolution SST and evaluate the model outputs and error structure before utilizing high-resolution products. Being able to use coarser resolution SST may also spare finer scale products for investigating the interactions of oceanographic features and movements.

\section{Benefits of a holistic approach}

Given how well TrackIt is able to estimate positions using only light, it is very tempting to perform SSTmatching outside of this model, i.e. reverting to a 2 -step approach. The first obvious drawback is that the uncertainties can no longer be described coherently. A unique aspect of the TrackIt model is that uncertainties in measurements and estimates are propagated all the way through the model, from the raw light and SST observations to track reconstruction. In fact, information throughout the whole track can help in estimating any individual waypoint, something extremely difficult to implement in a 2-step manner. This is especially true when SST-matching fails, perhaps due to some measurement errors in a tag or a satellite image. When this happens, the heuristic matching of SST values within a given area around a light-only estimated waypoint will not yield any viable positions. Yet, when SST is incorporated within a coherent model as in the case of TrackIt, the information elsewhere in the track can contribute to estimating a position (Fig. S2 in the supplement at www.int-res.com/articles/suppl/m419 p071_supp.pdf). The same advantage can be extended to any new type of observation, such as geomagnetic signals as they become available in the future generations of tags.

\section{A call for standardized double-tagging datasets}

A holistic approach for incorporating SST into TrackIt is presented here. Although it is desirable to provide more validation examples, particularly for the Atlantic Ocean, double-tag datasets are not easy to come by. It would be useful if in the near future, double-tag deployments occurred as part of a comprehensive tagging experiment or during product development by tag manufacturers, to allow validation of TrackIt and other geolocation methods. More importantly, double-tag datasets should be more easily accessible, perhaps offered through manufacturers as part of a diagnostic and open source tool development kit. Satellite radiotelemetry tags could also provide other relevant parameter estimates for the model. Nonetheless, the improvements of adding SST to TrackIt are already evident from the examples presented here, and demonstrate the potential of this model for assimilating new observation types.

Acknowledgements. This work was sponsored by the University of Hawai'i Pelagic Fisheries Research Program under cooperative agreement No. NA17RJ1230 from the National Oceanic and Atmospheric Administration (NOAA). We thank Dave Holts, Suzanne Kohin and the Southwest Fisheries Science Center for providing the mako shark data, and Michael Musyl for the drifter data. We acknowledge the NOAA CoastWatch Program, NOAA NESDIS Office of Satellite Data Processing and Distribution, and NASA Goddard Space Flight Center, and NASA Ocean Biology Processing Group for providing access to various satellite seasurface temperature products. We thank Dave Foley for sharing his ideas on the SST products, Vardis Tsontos for 
commenting on an early draft of this paper, and 3 anonymous reviewers for their thoughtful inputs. C. H. Lam was supported by the NASA Headquarters under the Earth and Space Science Fellowship Program Grant NNX08AU86H, and with additional sponsorship from the Winnie Wong Scholarship.

\section{LITERATURE CITED}

Arnold G, Dewar H (2001) Electronic tags in marine fisheries research: a 30-year perspective. In: Sibert JR, Nielsen JL (eds) Electronic tagging and tracking in marine fisheries reviews: methods and technologies in fish biology and fisheries. Kluwer Academic Press, Dordrecht, p 7-64

$>$ Domeier ML, Nasby-Lucas N (2008) Migration patterns of white sharks (Carcharodon carcharias) tagged at Guadalupe Island, Mexico, and identification of an eastern Pacific shared offshore foraging area. Mar Ecol Prog Ser 370:221-237

Domeier ML, Kiefer D, Nasby-Lucas N, Wagschal A, O'Brien F (2005) Tracking Pacific bluefin tuna (Thunnus thynnus orientalis) in the northeastern Pacific with an automated algorithm that estimates latitude by matching sea-surfacetemperature data from satellites with temperature data from tags on fish. Fish Bull 103:292-306

Ekstrom PA (2002) Inferring the surface irradiance from measurements made at depth. Available at: www.lotek.com /irradiance.pdf (accessed on November 24, 2010)

Ekstrom PA (2004) An advance in geolocation by light. Mem Natl Inst Polar Res (Jpn) 58(Spec Issue):210-226

Ekstrom PA (2007) Error measures for template-fit geolocation based on light. Deep-Sea Res II 54:392-403

Gentemann CL, Minnett PJ, Le Borgne P, Merchant CJ (2008) Multi-satellite measurements of large diurnal warming events. Geophys Res Lett 35, L22602, doi:10.1029/2008 GL035730

Greene CH, Block BA, Welch D, Jackson G, Lawson GL, Rechisky EL (2009) Advances in conservation oceanography: new tagging and tracking technologies and their potential for transforming the science underlying fisheries management. Oceanography (Wash DC) 22:210-223

Hill R (1994) Theory of geolocation by light levels. In: LeBoeuf B, Laws R (eds) Elephant seals: population ecology, behaviour, and physiology. University of California Press, Berkeley, p 227-236

Hill R, Braun M (2001) Geolocation by light level — the next step: latitude. In: Sibert JR, Nielsen JL (eds) Electronic tagging and tracking in marine fisheries. Kluwer Academic Publishers, Dordrecht, p 315-330

Lam CH, Nielsen A, Sibert JR (2008) Improving light and temperature based geolocation by unscented Kalman filtering. Fish Res 91:15-25

Meeus JH (1998) Astronomical algorithms, 2nd edn. Willmann-Bell, Inc., Richmond, VA

Musyl M, Brill R, Curran D, Gunn JS and others (2001) Ability of archival tags to provide estimates of geographical position based on light intensity. In: Sibert JR, Nielsen JL (eds) Electronic tagging and tracking in marine fisheries. Kluwer Academic Publishers, Dordrecht, p 343-368

Nielsen A, Sibert JR (2007) State-space model for light-based tracking of marine animals. Can J Fish Aquat Sci 64: 1055-1068

> Nielsen A, Bigelow KA, Musyl MK, Sibert JR (2006) Improv-

Editorial responsibility: Rory Wilson,

Swansea, UK ing light-based geolocation by including sea surface temperature. Fish Oceanogr 15:314-325

NOAA (2007) NOAA CoastWatch Program west coast regional node dataset summary for blended sea surface temperature. Available at http://coastwatch.pfel.noaa.gov/ infog/BA_ssta_las.html (accessed on November 24, 2010)

> Qayum HA, Klimley AP, Newton R, Richert JE (2007) Broadband versus narrow-band irradiance for estimating latitude by archival tags. Mar Biol 151:467-481

Reynolds RW, Smith TM (1994) Improved global sea-surface temperature analyses using optimum interpolation. J Clim 7:929-948

Reynolds RW, Smith TM, Liu C, Chelton DB, Casey KS, Schlax MG (2007) Daily high-resolution-blended analyses for sea surface temperature. J Clim 20:5473-5496

Royer F, Lutcavage M (2008) Filtering and interpreting location errors in satellite telemetry of marine animals. J Exp Mar Biol Ecol 359:1-10

Schaefer KM, Fuller DW (2006) Comparative performance of current-generation geolocating archival tags. Mar Technol Soc J 40:15-28

Sibert JR, Musyl MK, Brill RW (2003) Horizontal movements of bigeye tuna (Thunnus obesus) near Hawaii determined by Kalman filter analysis of archival tagging data. Fish Oceanogr 12:141-151

Sibert JR, Lutcavage ME, Nielson A, Brill RW, Wilson S (2006) Interannual variation in the large-scale movement of Atlantic bluefin tuna (Thunnus thynnus) determined from pop-up satellite archival tags. Can J Fish Aquat Sci 63: 2154-2166

Sibert JR, Nielsen A, Musyl M, Leroy B, Evans K (2009) Removing bias in latitude estimated from solar irradiance time series. In: Nielsen JL, Arrizabalaga H, Fragoso N, Hobday A, Lutcavage M, Sibert JR (eds) Tagging and tracking of marine animals with electronic devices, reviews: methods and technologies in fish biology and fisheries 9. Springer, Heidelberg, p 311-322

Smith P, Goodman D (1986) Determining fish movement from an 'archival' tag: precision of geographical positions made from a time series of swimming temperature and depth. Tech. Rep. NOAA-TM-NMFSSWFC-60, NOAA Technical Memorandum, NOAA, Silver Spring, MD

Teo SLH, Boustany A, Blackwell S, Walli A, Weng KC, Block BA (2004) Validation of geolocation estimates based on light level and sea surface temperature from electronic tags. Mar Ecol Prog Ser 283:81-98

Thygesen UH, Nielsen A (2009) Lessons from a prototype geolocation problem. In: Nielsen JL, Arrizabalaga $\mathrm{H}$, Fragoso N, Hobday A, Lutcavage M, Sibert JR (eds) Tagging and tracking of marine animals with electronic devices, reviews: methods and technologies in fish biology and fisheries 9. Springer, Heidelberg, p 257-276

Thygesen UH, Pedersen MW, Madsen H (2009) Geolocating fish using hidden Markov models and data storage tags. In: Nielsen JL, Arrizabalaga H, Fragoso N, Hobday A, Lutcavage $M$, Sibert JR (eds) Tagging and tracking of marine animals with electronic devices, reviews: methods and technologies in fish biology and fisheries 9. Springer, Heidelberg, p 277-293

Wilson R, Ducamp J, Rees W, Culik B, Neikamp K (1992) Estimation of location: global coverage using light intensity. In: Priede I, Swift S (eds) Wildlife telemetry: remote monitoring and tracking of animals. Ellis Horwood, New York, NY, p 131-134

Submitted: February 17, 2010; Accepted: October 4, 2010

Proofs received from author(s): November 26, 2010 